sciendo

\title{
Correspondence Via the Backdoor and Other Stories
}

Peter Alward

University of Lethbridge

Disputatio No. 8

May 2003

DOI: 10.2478/disp-2003-0001

ISSN: 0873-626X 
Disputatio 14, May 2003

\title{
Correspondence via the backdoor and other stories ${ }^{1}$
}

\author{
Peter Alward \\ U niversity of Lethbridge
}

Much has been written of late concerning the relative virtues and vices of correspondence and deflationary theories of Truth. W hat is troubling, however, is that it is not always entirely clear exactly what distinguishes the different conceptions of truth. Characterizations of the distinction are often vague and sometimes vary from writer to writer. ${ }^{2}$ O ne central thing I want to do here is to diagnose the source of the difficulty in providing a clear characterization of the distinction. In light of this diagnosis, I will argue that there is a simple distinguishing feature of such views. Roughly, the distinction depends on the modal status accorded to the T-sentences by the various conceptions. And finally, I will argue in favor of drawing the distinction in this way by showing that it yields a powerful method of arguing for or against a given conception of truth.

\section{Diagnosis}

There are two central issues that theorists about truth tend to grapple with: the nature of truth, and the meaning of the word 'true'. And these are, obviously, intimately related issues. O ne's account of the meaning of 'true' will, presumably, be informed by one's theory of the nature of truth. W hat I want to suggest, however, is that an impor-

${ }^{1}$ I would like to thank Dorit Bar-On, Claire Horisk, W illiam G. Lycan, Andrew Mills, Michael Resnik, and Keith Simmons for helpful comments on earlier drafts of this paper.

${ }^{2}$ See, e. g., Devitt (1991) p. 30, Field (1994) pp. 251-255, Leeds (1995) pp.

1-4, Resnik (1990) p. 413. 
tant reason why a clear account of the distinction between correspondence and deflationary theories of truth is hard to come by is that these theories address different issues. Correspondence theories are first and foremost theories of the nature of truth, while deflationary theories are theories about the meaning (or, perhaps less contentiously, the definition) of 'true'.

Let me elaborate. The fundamental dispute between correspondence theorists and deflationists, in my view, concerns whether or not truth has a nature, or whether or not there is a "genuine" property of being true, which purported truth bearers - sentences, propositions, and the like - can have or lack. According to correspondence theorists, truth does have a nature, and what a correspondence theory provides is an account of this nature. According to deflationary theorists, in contrast, truth does not have a nature. As a result, a deflationary theory cannot be a theory about the nature of truth (unless, of course, one counts the thesis that truth lacks a nature as a theory of its nature). The only theory a deflationist is in a position to offer is a theory of the meaning of 'true'. The challenge for a deflationist is to offer an account of the meaning of 'true' which does not presuppose that being true is a genuine property but which would still enable truth claims to serve the purposes for which we use them.

What I want to do is to distinguish between the deflationary and correspondence views in terms of the accounts they give of the meaning of 'true'. Strictly speaking, as I have characterized things, a correspondence theory is not a theory of the meaning of 'true' at all. By a correspondence account of meaning, I simply mean an account which implicates a genuine property of being true in its account of the meaning of 'true' (or, perhaps, of 'is true'). 3 But before the various accounts of truth can be distinguished in terms of the accounts they give of the meaning of 'true', we need to get clearer on what it would be for truth

\footnotetext{
${ }^{3}$ of course, there are a number of ways a property $P$ might be implicated in an account of the meaning of a predicate ' $F X^{\prime}$. O ne might, for example, allow the property itself serve as the meaning of the predicate. Or one might believe that the meaning of a predicate is an intension - a function from a class of arguments to truth values - and suppose that the intension of ' $F x^{\prime}$ is the function that gives the value 'true' for all and only those arguments that have the property P. Or one might even believe that the meaning of a predicate is an extension and suppose that the extension of ' $F x^{\prime}$ is the set of things that are $P$.
} 
to have a nature. To this end, I will begin by developing the correspondence account of the nature of truth.

\section{The nature of truth}

In this section, I want to characterize the correspondence account of the nature of truth. Two features of correspondence truth will emerge in this discussion which will serve to distinguish it from other accounts of truth. These features will enable us to compare the correspondence account with two alternatives accounts - "deflationism" and "quietism" - which differ from the correspondence theory in lacking one or the other of them. But before discussing the nature of truth, it is important to say a few things about what I take the bearers of truth to be.

\section{Truth bearers}

When questions concerning the modal status of $T$-sentences sentences such as ' $M$ ary is tall' is true if and only if Mary is tall' arise, it is commonplace to suppose that the issue depends on the nature of the truth bearers being considered. If the truth bearers are propositions, then, of course, the T-sentences are necessary. After all, propositions have the truth conditions that they do of necessity. And if the truth bearers are inscriptions or noises, then, of course, the Tsentences are contingent. After all, the truth conditions of inscriptions or noises depend on what they mean, and it is a purely conventional, and hence contingent, matter that a given sequence of symbols or sounds means what it does, or anything at all.

W hat I am going to argue is that correspondence and deflationary theories of the meaning of 'true' differ in the modal status they accord to $\mathrm{T}$-sentences involving the very same truth bearers. As a result, I do not want the necessity of the T-sentences to follow trivially from my choice of truth bearers. O ne obvious candidate, inscription types, is problematic because taking inscriptions to be truth bearers would seem to require taking accidentally formed tokens - tokens discernible in the tread pattern of a tire, for example - to have truth-values. A better suggestion would be to take the declarative sentences of a language (or of languages, in general) to be truth bearers. Care needs to be taken here, however. Sentences of abstract interpreted languages have their meanings, and hence their truth conditions, of necessity. If a 
given symbol $S$ which has meaning $m$ in an abstract language $L$ were to mean something other than $m$, it would not be an expression of $L$. Declarative sentences of natural languages, in contrast, have their meanings only contingently. To suppose otherwise would be to suppose that any local meaning change would result in a numerically distinct natural language.

Let me elaborate. The meanings of words of a natural language can and often do undergo change over time. As a result, the meanings of sentences containing those words can change as well. But such changes do not yield a distinct natural language: natural languages are not as transient as all that. Instead, the proper description of what has gone on is that the meanings of some of the sentences of the single natural language have undergone change. And if the meanings of sentences of natural languages can undergo change, then they have their meanings only contingently. Now one might just insist that when meaning change occurs, what results are distinct natural language words and sentences. This sounds quite odd to me but, of course, a charge of oddness falls far short of a decisive argument. So let me do some insisting of my own. I am simply going to stipulate that a natural language sentence is an inscription (or sequence of sounds) in use by a particular linguistic community: if we have the same inscription being used by the same community, we have the same sentence. ${ }^{4}$

Taking truth bearers to be the declarative sentences types of a natural language is an improvement, but a few glitches remain. To speak of declarative sentences is to speak of a grammatical category of expressions, and, notoriously, expressions of this category can be used in a number of very different sorts of speech acts. To alleviate such worries we might suppose that a given utterance is a token of the relevant sentence type only if it is used to express a belief, or make an assertion, or something along these lines. Finally, in order to avoid problems due to indexicality or ambiguity, it might be best to suppose that our truth bearers are sentence-context pairs. In what follows, however, I will simply assume that declarative sentence types of natural languages are the truth bearers in question.

It is important to be clear about exactly what my project is here. I am attempting to draw the distinction between deflationary and corre-

\footnotetext{
${ }^{4}$ Note: linguistic communities are like sport teams in that changes in membership do not result in numerically distinct communities. For a more developed account of word identity, see my "Between the Lines of Age."
} 
spondence accounts of truth on the assumption that (1) there is genuine issue of contention between the two views and (2) the issue has to do with the nature of truth. By (1), what I mean is that the deflationary and correspondence conceptions offer genuinely competing accounts of our concept of truth. What I want to rule out is the view that the two theories offer complementary accounts of truth, both of which we make use of on different occasions. ${ }^{5}$ If the two accounts were complementary, much of the literature on this issue would simply be misguided. And by (2), what I mean is that what is at stake in the dispute is the nature of truth per se and not the nature of truth bearers. As a result, I intend to compare what the two theories imply with respect to the same truth bearers.

Now it might be argued that by focusing on truth bearers that mean what they do only contingently, I end up presenting deflationism in an unfavourable light. After all, deflationary theories are specifically designed to account for the truth of propositions and interpreted sentences and the like. My reasons for focusing instead on the truth bearers that I do are twofold. First, doing so brings to the fore an interesting distinction between the two theories. And second, I think that there are such truth bearers. For the reasons sketched above, I think sentences of natural languages have their meanings only contingently. As a result, if deflationism is in the end to provide a complete account of truth, issues pertaining to such truth bearers will have to be addressed.

\section{Correspondence truth ${ }^{6}$}

According to the correspondence conception, truth has a nature: there is a "genuine" property of being true. W hat a correspondence theory offers is an account of what it is for a sentence to have the property of being true. Paradigmatically, a correspondence theory will

${ }^{5}$ Field, 1986, argues that we need both the deflationary and the correspondence conception of truth.

${ }^{6}$ M uch of what I say about correspondence truth would apply equally well to epistemic conceptions of truth. Deflationism stands in contrast to all such inflationist theories. I am simply using the correspondence theory as an exemplar of an inflationist truth theory, for present purposes. To defend correspondence truth, one would have to both argue against deflationism and argue that the correspondence theory is the best version of inflationism. 
characterize a relation - the "correspondence" relation - between sentences and facts or token states of affairs, and analyze the property of being true in terms of this relation: necessarily, a sentence, $S$, in a world, $i$, is true at a world, j, just in case there is, in $j$, a token state of affairs, $x$, such that $S$ stands in the correspondence relation to $x{ }^{7}$ Moreover, the correspondence relation can itself be analyzed in terms of two other relations: a relation between sentences and the members of some class of entities (typically meanings or entities determined by meanings) and a relation between such entities and states of affairs. Let us call the former relation the "means" relation and the latter the "obtains" relations. This yields the following account of the correspondence relation: necessarily, a sentence, $S$, in a world, $i$, stands in the correspondence relation to a state, $A$, in a world, j, just in case there is an entity, $y$, such that (i) in i, y stands in the means relation to $S$ and (ii) A stands in the obtains relation to $y^{8}$

Let me illustrate what I have in mind here with a simple version of the correspondence theory. Let us suppose, as has oft been suggested, that the meaning of a sentence is a set of possible worlds. (In order to allay worries about indexicality, it might be better to say that the meaning of a sentence on an occasion of use is a set of worlds). N ow we can analyze the "means" and "obtains" relations as follows: a set of worlds, $E$, stands in the means relation to a sentence, $S$, just in case $E$ is the meaning of $S$; and a world, $w$, stands in the obtains relation to a set of worlds, $E$, just in case $w$ is a member of $E .{ }^{9}$ This gives us the following account of the correspondence relation: necessarily, a sentence, $S$, used in a world, i, and a world, w, stand in the correspondence relation just in case there exists a set of worlds, $y$, such that (i) in

\footnotetext{
${ }^{7}$ It is important to note that the necessity operator must have wide scope. This is because, in giving an account of the nature of truth, one is asserting what property truth is, in the sense of identity.

${ }^{8} \mathrm{~N}$ ote: a correspondence theorist who resists taking meanings to be entities could take sentences to represent states of affairs which may or may not obtain. This would yield the following account of the correspondence relation: necessarily, a sentence, $S$, in a world, $i$, corresponds to the facts in a world, j, just in case there is a state of affairs, $A$, such that (i) in $i, S$ represents $A$, and (ii) in j, A obtains.

${ }^{9}$ Instead of talking about worlds standing in the obtains relation to a set of worlds, we could talk of a token state of affairs so standing: a token state of affairs $A$ stands in the obtains relation to a set of worlds $E$ just in case the world, w, of which $A$ is a part, is a member of $E$.
} 
$i, y$ is the meaning of $S$ and (ii) $w$ is a member of $y$. And finally, we get the following account of truth: necessarily, a sentence, $S$, in a world, i, is true at a world, $j$, just in case there is a set of worlds, $y$, such that (i) in $i, y$ is the meaning of $S$ and (ii) $j$ is a member of $y$.

There are, I think, two important features of correspondence theories which distinguish them from other accounts of the nature of truth. First, according to the correspondence conception, there is a genuine property that all true sentences have in common in virtue of being true. In the case of the simple correspondence theory considered above, all true sentences share the complex property of having as a meaning a set of worlds which itself has as a member the actual world. And second, a correspondence theory offers an explanation as to why sentences have the truth conditions that they do. The explanation our simple correspondence theory offers as to why 'J ohn is tall' is true just in case John is tall, for example, is as follows. The sentence 'John is tall' is true just in case the actual world is a member of the set which serves as its meaning. The set of worlds which serves as the meaning of 'John is tall' includes all and only those worlds in which John is tall. As a result, 'John is tall' is true if and only if John is tall in the actual world, that is, if and only if J ohn is tall.

\section{Deflationist truth}

The central alternative I wish to consider is that according to which there is no genuine property that all true sentences share in virtue of being true. This is, as I have characterized things, the deflationist account of the nature of truth. N ow, of course, there are two ways to deny that truth is a genuine property: one could deny that truth is a property at all; or one could allow that truth is a property but of a trivial or nongenuine sort. W hat the denial that truth is a property at all amounts to is the claim that sentences which make truth claims either do not have a subject-predicate form, despite surface grammatical appearances, or are a certain sort of nonsense. More needs to be said, however, about what the claim that truth is a property but of a trivial sort amounts to.

W hat I mean by a trivial property is a property which is what I shall call "maximally s-disjunctive". Corresponding to any property is a class 
of potential bearers of that property. ${ }^{10}$ And the class of potential bearers of a property can be broken up into subclasses in a number of different ways. Now an account of the nature of a property specifies a condition that has to hold in order for any given member of the class of potential bearers to have the property. A property is "s-disjunctive" just in case the condition that has to hold in order for an entity to have the property depends upon what subclass it is a member of. Consider by way of illustration, a property, being-a-member-of-team- $A$, whose potential bearers - a group of people in a gym - fall into two subclasses, men and women. And let us suppose that the members of the subclass of men are on team A just in case they are not wearing shirts, while the members of the subclass of women are on team A just in case they are wearing white T-shirts. This yields the following account of being-a-member-of-team- $A$ : necessarily, for any $x$ that is a member of the class of people in the gym, $x$ is on team $A$ just in case $x$ is a man and is shirtless, or $\mathrm{x}$ is a woman and is wearing a white shirt. And this would make being a member of team A. A property is "maximally $s$ disjunctive" just in case there is a distinct disjunct corresponding to each member of the class of potential bearers. ${ }^{11}$

${ }^{10}$ Exactly on what basis the class of potential bearers of a property is to be determined is a matter of some controversy (see, e.g., the literature on truthaptitude). The easiest thing might be to suppose that everything is a member of the class of potential bearers of any given property (perhaps qualified by certain type restrictions).

${ }^{11}$ W illiam G. Lycan has pointed out that as things have been characterized thus far, the property of being a dog is maximally s-disjunctive and, hence, trivial. Consider the following account of this property:

necessarily, $x$ is a dog just in case ( $x$ is Fido and $x$ has the property of being-Fido-and-canine) or ( $x$ is Rover and $x$ has the property of beingRover-and-canine) or ...

What is important to note, however, is that this analysis is equivalent to the following:

Necessarily, $\mathrm{x}$ is a dog just in case $\mathrm{x}$ is canine.

As a result, we know how to generalize the former account of Doghood in such a way so that we can generate disjuncts for any new dog candidate we encounter. In the case of a trivial property in contrast, there is no way to generalize from the disjuncts which characterize the property in order to generate a new disjunct for any new candidate bearer of the property we encounter. (If talk of new candidate bearers of the property gets you down, things might be better characterized as follows: given all but one of the 
Given this account of what it is for a property to be maximally sdisjunctive and, hence, trivial, by my lights, the following account of truth is one according to which truth is not a genuine property:

Necessarily, a sentence, $S$, in a world, i, is true at a world, j, just in case ( $S$ is 'it is snowing' and, in j, it is snowing) or ( $S$ is 'it is raining' and, in $j$, it is raining) or ( $\mathrm{S}$ is 'John is tall' and, in $\mathrm{j}$, John is tall) or... ,

where there is a separate disjunct for every sentence which is a member of the class of potential bearers. And this is an account of truth only a deflationist would love. ${ }^{12}$

\section{The meaning of 'true'}

W hat I want to argue here is that we can discover an important distinguishing feature of correspondence and deflationary theories when we focus on the accounts they give of the meaning of 'true'. By a correspondence theory of the meaning of 'true', I mean a theory which invokes the property of being true in its account of the meaning of 'true' (or 'is true'), where the nature of this property is to be understood along correspondence lines. And by a deflationary account of the meaning of 'true', I mean one which does not implicate any such property in its account of the meaning of 'true'. Now what I want to suggest is that it follows from the correspondence account of meaning that the T-biconditionals - sentences of the form ' $p$ ' is true iff $p$ ' are contingent. They are true in virtue of facts having to do with meanings of our sentences; but they are contingent because our sentences might have had different meanings. But, as I shall argue, if a deflationary theory of the meaning of 'true' is to yield the truth of the T-biconditionals at all, it will have to yield the stronger result that they are necessary truths. Hence, we can distinguish between correspondence and deflationary theories of truth on the basis of the modal status

disjuncts in the account of a trivial property, there is no way to determine what the final disjunct is).

12 There is another account of the nature of truth, different from both the correspondence and deflationary accounts, which I call "Q uietism". This account differs from the deflationary account in that it allows that truth is a genuine property, but it differs from the correspondence account as well in that it offers no explanation as to why sentences have the truth conditions that they do. See, e.g., Davidson (1967). 
they (or their associated theories of meaning) attribute to the $T$ sentences.

\section{Correspondence 'true'}

Consider, first, the correspondence account of the meaning of 'true'. For illustrative purposes, let us suppose once again that the meaning of a sentence is a set of possible worlds. Moreover, let us utilize the following simple account of the meanings of subsentential components: the meaning of a directly referential singular term, such as a proper name, is an object, namely its referent; and the meaning of a predicate is a function which takes objects as arguments and yields sets of worlds as values. So, for example, we might suppose that the meaning of 'John' is a person John, and that the meaning of the predicate 'is tall' is a function from objects to a set whose members are worlds in which those objects have the property of being tall. This would yield as the meaning of 'John is tall' a set of worlds in which John has the property of being tall.

N ow, given this account of meaning, the meaning of 'is true' would have to be, according to a correspondence theory, a function from sentences to sets whose members are worlds in which the sentences have the property of being true. And given the correspondence account of the nature of the property of being true, each of these will be a world, w, in which the sentence in question has as its meaning a set of worlds which includes $w$. This yields as the meaning of, for example, 'John is tall' is true' a set which includes worlds in which the meaning of 'John is tall' is a set consisting of all and only those worlds in which John is tall and in which John is tall, as well as worlds in which the meaning of 'John is tall' is a set consisting of all and only those worlds in which Gary is short and in which Gary is short.

Let me illustrate what I have in mind here. In what follows, ' $T j$ ' will abbreviate 'John is tall', 'Gs' will abbreviate 'Gary is short', and ' $M(p)$ ' will abbreviate 'the meaning of (sentence) $p$ '. Now let us suppose there are exactly four worlds - wa, wb, wc, and wd which can be characterized as follows:

wa: $T j \& \sim G s ; M(' T j ')=\{w a, w b\}$

wb: Tj \& $\sim G S ; M\left(' T j^{\prime}\right)=\{w C, w d\}$

WC: $G s \& \sim T j ; M\left({ }^{\prime} T j^{\prime}\right)=\{w C, w d\}$

$w d: G s \& \sim T j ; M\left({ }^{\prime} T j^{\prime}\right)=\{w a, w b\}$ 
The meaning of 'John is tall' is true' relative to these worlds would be the set $\{w a, w c\}$. This is because wa and wc are the only worlds which are themselves members of $M\left({ }^{\prime} T j^{\prime}\right)$ at that world.

It is easy to show that a T-biconditional such as "John is tall" is true iff John is tall' is true in the actual world, given the correspondence account of truth. The meaning of 'John is tall' in the actual word is a set consisting of all and only those worlds in which J ohn is tall, that is, $M\left({ }^{\prime} T j^{\prime}\right)=\{w: T j @ w\}$. Now suppose the left-hand side of the biconditional is true, that is, that 'John is tall' is true' is true. This would mean that the actual world, $a$, is a member of $M\left({ }^{\prime} T j^{\prime}\right)$ in $a$. But this just means that a is a world in which John is tall. Suppose now that the lefthand side is false, that is, that ' John is tall' is true' is false. This would mean that the actual world, $a$, is not a member of $M\left({ }^{\prime} T j^{\prime}\right)$ in $a$. And this just means that a is not a world in which John is tall.

But it is important to note that if 'J ohn is tall' had had a different meaning, this T-biconditional might not have been true. Consider, for example, a world, b, in which John is tall and Gary is not short and in which the meaning of 'John is tall' is a set consisting of all and only worlds in which Gary is short (i.e., $\left.M\left({ }^{\prime} T j^{\prime}\right)=\{w: G s @ w\}\right)$. Since $b$ is not a member of $M(' T j$ ') in $b$, 'John is tall' is false at $b$. But since John is tall at this world, the T-biconditional "John is tall' is true iff John is tall' is false as well. Hence, it follows from the correspondence account of the meaning of 'true' that the T-biconditionals are true, but only contingently so. ${ }^{13}$

\section{Deflationary 'true'}

Let us turn now to deflationary accounts of the meaning of 'true'. Recall: the challenge for the deflationist is to give an account of the meaning of 'true' which does not presuppose that truth is a genuine property. There are two central approaches one might take towards offering some such theory. O ne might suppose that sentences which makes truth claims have a genuine subject-predicate form - that is, that 'is true' is a predicate - but that only a trivial property need be implicated in an account of the meaning of 'is true'. Or one might suppose that sentences that make truth claims do not have subject-

${ }^{13}$ N ote: the modal status of T-biconditionals depends on their meanings in the actual world, not on the meanings they have in other possible worlds. 
predicate form - that is, that 'is true' is not a predicate - and offer an account of the meaning of 'true' which is amenable to the alternate form such sentences are taken to have.

1. First, let us consider deflationary theories according to which 'is true' is a predicate. Given the simple account of meaning we have been working with, the meaning of 'is true' would have to be a function from sentences to sets of worlds. And the members of such sets would have to be worlds in which sentences have the property of being true. But, on the deflationist story, this property will have to be of a trivial sort. In particular, it will have to be a maximally s-disjunctive property. That is, it will have to be a property of the following form:

Necessarily, for any sentence, $x, x$ is true just in case ( $x$ is 'it is snowing' and C1) or ( $x$ is 'it is raining' and C2) or ( $x$ is 'John is tall' and C3) or

where $\mathrm{C} 1, \mathrm{C} 2, \mathrm{C} 3, \ldots$ are just conditions, or, perhaps, types of situations. As a result, the meaning of, for example, "John is tall' is true' will be a set of worlds in which conditions $\mathrm{C} 3$ are met. If conditions C3 are met just in case John is tall, then these will be worlds in which John is tall; and if they are met just in case Simone is French, then these will be worlds in which Simone is French. true:

Now recall the following (trivial) account of the property of being

H) Necessarily, for any sentence, $x, x$ is true just in case ( $x$ is 'it is snowing' and it is snowing) or ( $\mathrm{x}$ is 'it is raining' and it is raining) or ( $\mathrm{x}$ is 'J ohn is tall' and John is tall) or ....

W hat I want to argue is that if a deflationist accepts this account of the nature of the property of truth, the T-biconditionals will, on her view, be necessary. But if a deflationist takes truth to be some other maximally s-disjunctive property, (some of) the T-biconditionals will, on her view, be false.

Suppose, first, that the account of truth appealed to is distinct from that given by $(H)$. For example, we might suppose the disjunct ' $(x$ is 'John is tall' and John is tall)' to be replaced with ' $(x$ is 'John is tall' and Simone is French)'. Moreover, let us suppose that Simone is French but John is not tall. The meaning of 'John is tall' is true' will, in this case, be a set of worlds in which Simone is French, and so "John 
is tall' is true' will be true. The meaning of 'J ohn is tall' will be a set of situations in which John is tall, and so 'John is tall' will be false. Hence, the T-biconditional "John is tall' is true iff John is tall' will be false.

Second, let us suppose that $(H)$ gives the nature of the property of being true. The meaning of ' John is tall' is true' will be a set containing all and only those worlds in which John is tall, as will the meaning of 'John is tall'. As a result, the right-hand side and the left-hand side of the T-biconditional 'John is tall' is true iff John is tall' mean the same. And, so, the right-side and the left hand side of the biconditional will have the same truth values in all possible circumstances, which makes the biconditional necessary.

2. O ne might object here that I have presupposed that any account of the meaning of a predicate has to implicate a property in some way. ${ }^{14}$ But the meaning of a predicate can also be given by means of a definition. O ne can, however, distinguish between correspondence and deflationary definitions of truth in a way that is closely analogous to the way deflationary and correspondence accounts of the meaning of 'is true' are distinguished above. W e can characterize a "maximally sdisjunctive definition" of a predicate as one which has a separate clause for each member of the "class of potential satisfiers" of the predicate. And we might suppose that according to deflationism, only a maximally s-disjunctive definition of truth can be given. But according to correspondence theorists, a "substantial definition" of truth can be given in terms of one or more other predicates (where the meanings of these predicates are neither maximally s-disjunctive properties nor maximally s-disjunctive definitions).

The obvious maximally s-disjunctive definition of truth is, roughly, the following:

DD) ' $x$ is true' $=d f$. ' $x$ is 'it is snowing' and it is snowing) or ( $x$ is 'it is raining' and it is raining) or ( $x$ is 'John is tall' and John is tall) or ...' ${ }^{15}$

And since the T-biconditionals follow from $D D$ ), they are true by definition and, hence, necessary. A typical correspondence definition of truth, in contrast, would be something like the following:

\footnotetext{
${ }^{14}$ See footnote \# 7.

${ }^{15}$ Field (1994) and Resnik (1990) defend something along these lines.
} 
DC) ' $x$ is true' $=d f$. 'there is a meaning, $y$, and an actual token state of affairs, $z$, such that $y$ stands in the means relation to $x$ and $z$ stands in the obtains relation to $y^{\prime}$.

And since the T-biconditionals follow from DC) only when combined with contingent meaning claims, they are contingent.

3. Second, let us consider deflationary accounts of the meaning of 'true' according to which 'is true' is not a predicate. The central approach along these lines is that which treats sentences which make truth claims as "prosentences". ${ }^{16}$ The basic idea here involves modelling the semantics of sentences of the form ' $S$ is true' on that of pronouns like 'he'. O ne standard approach to the meaning of pronouns makes use of Kaplan's distinction between character and content. ${ }^{17}$ Roughly, character of an expression is a function from contexts of use to content. (Note: for the sake of consistency with what has gone on above, I will suppose that the content of a sentence is a set of worlds.) W hat is distinct about pronouns is that, although they have meaning in the sense of character, they have no context independent content. An account of the meaning of a pronoun is exhausted by giving an account of its character. And this involves specifying how the content, that is, the referent, of a pronoun depends on features of the context in which it is used. So, for example, the character of ' $I$ ' is the function whose value in a given context of utterance is the speaker in that context.

N ow the character of a prosentence will have to be a function from contexts of utterance to sentence contents, which we will continue to suppose are sets possible worlds. So if a deflationist is to suppose that, for example, 'John is tall' is true' is a prosentence, an account of how the content of this sentence depends upon the context in which it is uttered must be forthcoming. Moreover, this account will have to yield the truth of the T-biconditionals. Suppose in a given context, $C$, the character of 'John is tall' is true' yields, as the content of this sentence in $\mathrm{C}$, a set of worlds which is distinct from the meaning of 'John is tall'. For example, we might suppose that the value of the

\footnotetext{
${ }^{16}$ See, e.g., Grover, Camp, and Belnap, 'A Prosentential Theory of Truth', Philosophical Studies 27,1975, and Robert Brandom 'Pragmatism, Phenomenalism, and Truth Talk', Midwest Studies in Philosophy XII, 1987. Strictly speaking, what Grover et al and Brandom are concerned with is truth as a property of propositions as opposed to sentences.

17 David Kaplan, 'D emonstratives', Themes From Kaplan, Almog, Perry, W ettstein, eds., 0 xford U niversity Press, 1989.
} 
character of "John is tall' is true' in C is a set of worlds in which Simone is French. But if this were the case, it might turn out that the T-biconditional 'J ohn is tall' is true iff J ohn is tall' is false. After all, it might turn out that Simone is French but John is not tall. So the content of "John is tall' is true' in C will have to be the same as that of 'John is tall'. Moreover, the same is true of any other context of utterance. The upshot of all this is that the character of "John is tall' is true' will have to be a constant function whose value is the same as the meaning of 'J ohn is tall', in all contexts of utterance. And since "John is tall' is true' and 'John is tall' mean the same in all contexts of utterance, their associated T-biconditional will be necessary in all contexts. $^{18}$

4. What I want to conclude here is that correspondence and deflationary accounts of the meaning of 'true' can be distinguished in terms of the modal status they accord to the T-biconditionals. According to the correspondence account, the T-biconditionals are contingent. And according to the deflationary account, the T-biconditionals are necessary. It is worth emphasizing that the argument I have given for this conclusion is more suggestive than conclusive. I have offered no in principle reason to suppose that there could be no account of the meaning of 'is true' which does not implicate the genuine property of truth, and which yields both the truth and the contingency of the $T$ biconditionals. But the burden is on the deflationist who objects to the necessity of the T-sentences to show that some such account is forthcoming.

\section{Correspondence via the backdoor}

In this section, I will illustrate the utility of formulating the distinction between the various conceptions of truth in terms of the logical status they accord to the T-sentences. The reason that formulating things in this way is useful is that doing so provides us with a clear and powerful method of arguing for or against any of the various concep-

\footnotetext{
${ }^{18}$ An alternative approach to the meaning of 'true' according to which 'is true' is not a predicate might be an expressivist account. The meaning of "John is tall' is true' might be analyzed as "John is tall' hooray!' (or perhaps something a little more sophisticated). The obvious problem for this sort of approach is that it is quite unclear how it would yield the T-biconditionals at all.
} 
tions. This methodology involves looking at arguments - or, more broadly, patterns of reasoning - which include T-sentences as premises. Since the validity of an argument often depends on the logical statuses of its premises, the validity of an argument involving $\mathrm{T}$ sentences will often depend upon which conception of truth is the correct one. Therefore, by defending or criticizing a pattern of reasoning which involves T-sentences one can thereby argue in favor of or against one the conceptions of truth.

Let us consider, by way of illustration, the following argument:

P1) If we had used our words differently, it might have been the case that 'grass is white' is true ${ }^{19}$

P2) 'Grass is white' is true iff grass is white

C) If we had used our words differently, it might have been the case that grass is white.

Now clearly $(C)$ is false - the colour of grass seems entirely independent of how we use our words. And certainly (P1) is intuitively true - if the word 'grass' meant what 'snow' in fact means then 'grass is white' would be true. Now if the correspondence conception were correct, then this argument would be invalid, because 'grass is white' would be substitutable for ' $g r a s s$ is white' is true' only in extensional contexts (or in counterfactual contexts in which our words are used as they, in fact, are). But if the deflationary conception were correct, then this argument would be valid. After all, if "grass is white' is true iff grass is white' is necessary, 'grass is white' can be substituted salva veritate for ' "grass is white' is true' in all counterfactual contexts. And so unless one could provide a reason for thinking that (P1) is false or (C) is true, this counts against the deflationary conception. ${ }^{20}$

A second, somewhat more contentious, illustration involves the role truth plays in explanations of success. Suppose an individual $A$ is successful at an activity $Q$, and we want to explain A's success. Let us

\footnotetext{
${ }^{19}$ I take this to be equivalent to "If we had used our words differently, 'grass is white' might have been true." The version in the body of the text makes the inference in question more perspicuous.

${ }^{20}$ Field argues (1994, pp. 277-278) that we can suppose that (P1) is false without "gratuitously departing from common sense".
} 
suppose, for the sake of the following explanation, that being in a belief state involves standing in a relation to a sentence. Moreover, let us suppose a belief-state is T-reliable just in case if a person is in that state, then the truth conditions of the sentence to which $s /$ he is thereby related probably obtain. ${ }^{21}$ In light of this, we might explain A's success at $Q$ as follows:

1) Success at $Q$ is achieved by doing $R$ in circumstances $C$

2) A's strongest desire is to be successful at $Q$

3) A believes that success at $Q$ is achieved by doing $R$ in circumstances $C$

4) A usually does what she believes will get her what she most wants

5) A's standing in the belief relation to sentence $S$ is T-reliable

6) $S$ is true iff $C$.

Typically, people require that explanations support certain counterfactuals. N ow if we require that this explanation of $A^{\prime}$ 's success support the following counterfactual, then we have grounds for preferring the correspondence conception of truth over the deflationary conception:

$\left(C_{f}\right)$ If the meaning of $S$ were not a set $\mathrm{C}$-worlds, then $\mathrm{A}$ would not have been successful.

Since according to the deflationary conception, the T-sentences are necessary, (6) would hold even in counterfactual circumstances in which the meaning of $\mathrm{S}$ was not a set of $\mathrm{C}$-worlds. Hence, assuming that (1)-(5) hold as well in such circumstances, it follows that on the deflationary conception A would have been successful even had not $\mathrm{S}$ meant that $\mathrm{C}$. According to the correspondence conception, in contrast, given that the T-biconditionals depend contingently on meaning, (6) would not hold in the relevant counterfactual circumstances. As a result, if the correspondence conception is correct, the explanation would support the counterfactual in question, as we have been supposing it should. 22,23

\footnotetext{
${ }^{21}$ A debt is owed to Field, 1986, for much of the setup here.

22 I have defended this argument in greater detail in Alward 1996.

${ }^{23}$ Field - (1986) p. 58 and (1994) p. 266 - offers an argument for deflationism using this methodology.
} 


\section{Conclusion}

The debate between advocates of deflationary and correspondence conceptions of truth has suffered from unclarity concerning the nature of the distinction. W hat I have done here is to offer a precise formulation of the distinction in terms of differences in the logical statuses the various conceptions accord to the T-sentences. And I have demonstrated the utility of this way of formulating the distinction by illustrating a methodology it yields for arguing for or against the various conceptions.

It should be noted, however, that arguing for the correspondence theory of truth from the contingency of the T-sentences is fraught with much greater obstacles than is arguing against the deflationary conception in this way. 0 ne would need to argue both that properties need to implicated in an account of the meaning of predicates such as 'is true', and that the correspondence account of the nature of truth is preferable to any other inflationist account. And inferential role theorists about meaning would likely object on the first count, while verificationists about truth would likely object on the second. But an argument for the contingency of the T-biconditionals is sufficient to undermine deflationism.

Peter Alward

Dept. of Philosophy

University of Lethbridge

4401 U niversity Dr.

Lethbridge, Alberta, T1K 3M 4

peter.alward@uleth.ca

\section{References}

Alward, Peter. 1996. Correspondence on the Cheap. Pacific Philosophical Quarterly 77.

- - Between the Lines of Age: Reflections of the Metaphysics of W ords. Unpublished manuscript.

Brandom, Robert, 'Pragmatism, Phenomenalism, and Truth Talk', Midwest Studies in Philosophy XII.

Davidson, Donald. 1967. Truth and M eaning. Synthese 17:304-23.

--.1996 . The Folly of Trying to D efine Truth. Journal of Philosophy 93. 
Devitt, Michael. 1991. Realism and Truth. $2^{\text {nd }}$ edition. Oxford: Blackwell.

Field, Hartry. 1972. Tarski's Theory of Truth. Journal of Philosophy 69.

- - (1986), 'The Deflationary Conception of Truth', Fact, Science, and Morality, MacDonald and W right, eds., Oxford, Basil Blackwell.

- - 1994. Deflationary Theories of Meaning and Content. Mind 103:249-84.

Grover, Camp, and Belnap. 1975. A Prosentential Theory of Truth. Philosophical Studies 27.

Horwich, Paul. 1990. Truth. Oxford: Blackwell.

Kaplan, David. 1989. Demonstratives. In Themes From Kaplan. Almog, Perry, W ettstein, eds. 0 xford: 0 xford U niversity Press.

Leeds, Stephen. 1995. Truth, Correspondence, and Success. Philosophical Studies 79.

Resnik, Michael. 1990. Immanent Truth. Mind 99:405-24. 